\title{
Effect of glycation on sodium caseinate-stabilized emulsions obtained by ultrasound
}

\author{
M. Corzo-Martínez, ${ }^{*}$ A. C. Soria, ${ }^{\star}$ M. Villamiel, ${ }^{*}$ A. Olano, ${ }^{*}$ F. M. Harte, $†$ and F. J. Moreno ${ }^{* 1}$ \\ *Instituto de Fermentaciones Industriales-CIAL (CSIC), 328006 Madrid, Spain \\ †Department of Food Science and Technology, The University of Tennessee, Knoxville 37996
}

\begin{abstract}
This work explores the potential of high-intensity ultrasound to produce fine-dispersion, long-time-stable, oil-in-water emulsions prepared with native and glycated bovine sodium caseinate (SC). Regardless the ultrasound amplitude and time assayed, the sonicated emulsions of native $\mathrm{SC}$ at $0.5 \mathrm{mg} / \mathrm{mL}$ had much higher emulsifying activity indexes compared with those emulsions formed by Ultra-Turrax (IKA Werke GmbH \& Co., Staufen, Germany) homogenization. Nevertheless, the native SC emulsions were very unstable despite the optimization of parameters such as protein concentration, amplitude of ultrasound wave, and sonication time by using a Box-Behnken design. Early glycation of SC with either galactose, lactose, or $10 \mathrm{kDa}$ dextran substantially improved both emulsifying activity and the stability, whereas at advanced stages of glycation, SC emulsions showed notably reduced emulsifying properties, likely because extensive glycation of SC promoted its polymerization mainly through covalent cross-linking, as was demonstrated by particle size measurements. The increase in particle diameter of glycoconjugates likely affected the diffusion of SC from bulk to the oil-water interface and slowed the reorientation process of the protein at the interface. These findings show that the combined effect of early-stage glycation of SC and high-intensity ultrasound as an emergent technique to form emulsions has the potential to provide improved emulsions that could be used in several food applications.
\end{abstract}

Key words: emulsion, Maillard reaction, sodium caseinate, ultrasound

\section{INTRODUCTION}

Dairy proteins, such as sodium caseinate (SC), are widely used in the food industry as functional ingredients because of their simple production, excellent

Received June 21, 2010.

Accepted September 12, 2010.

${ }^{1}$ Corresponding author: j.moreno@ifi.csic.es nutritional value, and versatile techno-functional properties (Ennis and Mulvihill, 2000; Fechner et al., 2007). Sodium caseinate is commercially employed as an emulsifier and stabilizer of oil-in-water $(\mathbf{O} / \mathbf{W})$ emulsions in many food systems, such as ice cream, cream liqueurs, whipped toppings, coffee whiteners, and products for infant nutrition, because of its pronounced amphiphilic nature, flexible structure, and relatively small molecule size. This enables it to quickly and strongly adsorb at the oil-water interface, lowering the interfacial tension and protecting dispersions by a combination of electrostatic repulsion and steric stabilization against immediate recoalescence, creaming, and flocculation during subsequent storage (Akinshina et al., 2008; O'Regan and Mulvihill, 2009).

On the other hand, during the last several years, the food industry has moved toward the search for procedures to obtain new ingredients with improved functional properties. With the aim of enhancing its emulsifying properties and expanding its industrial application, physical, enzymatic, and chemical modifications have been applied to change SC conformation and physicochemical properties, such as flexibility, hydrophilicity, viscosity, and charge. Among the studied chemical modifications, substantial evidence exists that controlled incubation of proteins with reducing sugars of different molecular weights to form glycoconjugates via the Maillard reaction (MR) is an economically profitable, efficient method to improve emulsifying properties, and it is a food-grade process (Oliver et al., 2006a).

Caseins and SC have been conjugated under controlled conditions with different mono-, di-, oligo-, and polysaccharides, including glucose, ribose, fructose, lactose, fructooligosaccharides, maltodextrins, pectins, and dextran; these glycoconjugates exhibit enhanced emulsifying properties over the native protein (Shepherd et al., 2000; Darewicz and Dziuba, 2001; Morris et al., 2004; Aminlari et al., 2005; Einhorn-Stoll et al., 2005; Oliver et al., 2006b; Fechner et al., 2007).

In the aforementioned studies, $\mathrm{O} / \mathrm{W}$ emulsions were formed by several methods of mechanical emulsification, with rotor-stator devices and high-pressure homogeniz- 
Table 1. Selected incubation conditions of sodium caseinate (SC) with galactose (Gal), lactose (Lac), and $10 \mathrm{kDa}$ dextran (DX 10 ) to obtain glycoconjugates for further analysis

\begin{tabular}{llll}
\hline Glycoconjugate & $\begin{array}{l}\text { Incubation } \\
\text { conditions }\end{array}$ & Structural features & $\begin{array}{l}\text { State of the } \\
\text { Maillard reaction }\end{array}$ \\
\hline SC:Gal & $60^{\circ} \mathrm{C}, 4 \mathrm{~h}$ & High glycation and no aggregation & Early \\
& $50^{\circ} \mathrm{C}, 72 \mathrm{~h}$ & High glycation and aggregation & Advanced \\
SC:Lac & $60^{\circ} \mathrm{C}, 8 \mathrm{~h}$ & Low glycation and no aggregation & Advanced \\
SC:DX & $60^{\circ} \mathrm{C}, 24 \mathrm{~h}$ & High glycation and low aggregation & Early \\
& $60^{\circ} \mathrm{C}, 8 \mathrm{~h}$ & Low glycation and no aggregation & Advanced \\
\hline
\end{tabular}

ers being the most commonly applied systems. However, these processes can be extremely inefficient, with most of the power being dissipated as heat (Behrend and Schubert, 2000; Dickinson, 2009). High-intensity ultrasound (HI-US) has received great attention as an alternative to conventional emulsification systems (Pongsawatmanit et al., 2006; Gaikwad and Pandit, 2008; Patist and Bates, 2008; Soria and Villamiel, 2010). The main physical phenomenon occurring during ultrasound (US) emulsification is cavitation, which consists in the formation, growth, and implosive collapse of bubbles in a liquid, causing intensive shock waves in the surrounding liquid and the formation of liquid jets of high velocity (Lauterborn and Ohl, 1997). Cavitational collapse at or near the interface produces very efficient droplet disruption, so that, on the whole, US is known to allow formation of very fine and highly stable emulsions with relatively low ultrasonic energy input and less surfactant compared with mechanical emulsification techniques (Bondy and Söllner, 1935; Knorr et al., 2004; Hielscher, 2005; Cucheval and Chow, 2008; Camino et al., 2009). However, to the best of our knowledge, despite the potential of protein glycation via the Maillard reaction and HI-US to improve emulsion formation and stability, no research on their combined effect on emulsifying properties of SC has been conducted.

Thus, the aims of this study were to (1) optimize the US operating conditions giving rise to $\mathrm{O} / \mathrm{W} \mathrm{SC}$ emulsions with enhanced emulsifying properties, and (2) evaluate the effect of glycation extent and molecular weight of attached carbohydrates - galactose $(\mathbf{G a l})$, lactose (Lac), and $10 \mathrm{kDa}$ dextran $\left(\mathbf{D X}_{10}\right)$ - on the emulsifying activity and stability of bovine SC.

\section{MATERIALS AND METHODS}

\section{Glycation of SC with Gal, Lac, and $10 \mathrm{kDa} D X_{10}$}

Dextran with an average molecular weight of $10 \mathrm{kDa}$, produced by Leuconostoc mesenteroides strain 151-877, was dialyzed versus deionized water using Spectra/Por 3 Biotech dialysis membrane tubing (3.5-kDa molecular weight cut-off; Spectrum Europe, Breda, the Netherlands) to remove low-molecular-weight oligosaccharides. Later, protein-sugar combinations were prepared at the following weight ratios: 1:0.2 for SC:Gal/Lac, and 1:2 for SC:DX ${ }_{10}$ mixtures (Corzo-Martínez et al., 2010). For this, carbohydrates (Gal/Lac/DX ${ }_{10}$; Sigma-Aldrich, St. Louis, MO) and bovine SC (Rovita FN 5, Proveedora Hispano Holandesa, S.A., Barcelona, Spain) were dissolved in $0.1 \mathrm{M}$ sodium phosphate buffer, $\mathrm{pH} 7.0$ (Merck, Darmstadt, Germany), and frozen at $-20^{\circ} \mathrm{C}$ for subsequent lyophilization. The freeze-dried proteincarbohydrate mixtures were incubated under vacuum in a desiccator equilibrated at water activity $\left(\boldsymbol{a}_{\mathrm{w}}\right)$ of 0.67 (Oliver et al., 2006b) with a saturated solution of $\mathrm{CuCl}_{2}$ (Sigma-Aldrich), and under the conditions detailed in Table 1. Such incubation conditions were selected based on the results derived from previous work in our laboratory (Corzo-Martínez et al., 2010). Thus, with the purpose of studying the effect of glycation extent on the SC emulsifying properties, selected incubation conditions were those that led to glycoconjugates at the early and advanced stages of the MR with different levels of glycation and aggregation as a function of carbohydrate reactivity (Table 1 ). In addition, the corresponding controls of SC also were prepared: (1) SC incubated without reducing sugars under the same experimental conditions (control heated SC), and (2) controls formed by SC and carbohydrate separately heated and mixed just before analysis (control heated $\mathrm{SC}+$ carbohydrate).

All incubations were performed in triplicate. After incubation, all samples were stored at $-20^{\circ} \mathrm{C}$ until analysis.

\section{Particle Size Determination}

Apparent particle diameter of SC:Gal/Lac/DX 10 conjugates (solutions at 3\% wt/vol in double-distilled water) was measured by photon correlation spectroscopy using a Delsa Nano C particle analyzer (Beckman-Coulter, Fullerton, CA). Average diameter was calculated as the average of 70 autocorrelation functions ( $165^{\circ}$ angle; 20 $\mu \mathrm{m}$ pin hole; $1 \%$ attenuation; $>10 \mathrm{Kcps})$. 
Table 2. Factors and levels used in the Box-Behnken design

\begin{tabular}{lll}
\hline $\begin{array}{l}\text { Sodium caseinate } \\
\text { concentration }(C, \mathrm{mg} / \mathrm{mL})\end{array}$ & $\begin{array}{l}\text { Ultrasound wave } \\
\text { amplitude }(A, \%)\end{array}$ & $\begin{array}{l}\text { Sonication } \\
\text { time }(t, \mathrm{~s})\end{array}$ \\
\hline $0.5(-1)$ & $20(-1)$ & $20(-1)$ \\
$2.5(0)$ & $40(0)$ & $40(0)$ \\
$4.5(+1)$ & $60(+1)$ & $60(+1)$ \\
\hline
\end{tabular}

\section{Preparation of O/W Emulsions}

Ultrasound Emulsification. One milliliter of sunflower oil and $4 \mathrm{~mL}$ of a native SC solution in $0.1 \mathrm{M}$ sodium phosphate buffer at $\mathrm{pH} 7.0$ were mixed together and then emulsified using a 450 digital sonifier (Branson Ultrasonics Corp., Danbury, CT), which comprised a tapered microtip (3.2 $\mathrm{mm}$ diameter, maximum wave amplitude of $120 \mu \mathrm{m})$ directly attached to a disruptor horn $(20 \mathrm{kHz}, 400 \mathrm{~W}$ full power $)$. The emulsification process was carried out at controlled temperature $\left(<30^{\circ} \mathrm{C}\right)$ by immersing the samples in an ice-water bath and at $1 \mathrm{~atm}$ as an increase in ambient pressure has been found to suppress cavitation partially (Canselier et al., 2002).

To optimize the US emulsification process, the effect of 3 experimental factors (unmodified SC concentration, $C, \mathrm{mg} / \mathrm{mL}$; US wave amplitude, $A, \%$; and sonication time, $t, \mathrm{~s})$ on emulsifying activity (EAI) and stability $(\Delta \mathbf{E A I}, \%)$ indices were evaluated using a 15 -run BoxBehnken design with 3 center points to estimate the experimental error. The low, middle, and high levels of each factor, designated as $-1,0$, and +1 respectively, are described in Table 2. Whereas the range for emulsifier concentration was selected based on data from the literature (Moreno et al., 2002; Oliver et al., 2006b; O'Regan and Mulvihill, 2009), the range for amplitude and sonication time was set based on limitations of instrumentation (70\% maximum amplitude for this tip) and preliminary assays carried out to determine extreme experimental conditions providing sample temperatures below $40^{\circ} \mathrm{C}$.

The relationships among the studied variables can be fitted by the following quadratic polynomial equation:

$$
\begin{aligned}
R & =\beta_{0}+\beta_{1} C+\beta_{2} A+\beta_{3} t+\beta_{1,1} C^{2}+\beta_{2,2} A^{2} \\
& +\beta_{3,3} t^{2}+\beta_{1,2} C A+\beta_{1,3} C t+\beta_{2,3} A t+\varepsilon
\end{aligned}
$$

where $R$ is the variable response (EAI or $\Delta \mathrm{EAI} \%$ ); $\beta_{0}$ is a constant; $\beta_{1}, \beta_{2}$, and $\beta_{3}$ are linear coefficients; $\beta_{1,1}$, $\beta_{2,2}$, and $\beta_{3,3}$ are quadratic coefficients; $\beta_{1,2}, \beta_{1,3}$, and $\beta_{2,3}$ are cross-product coefficients; and $\varepsilon$ is the error variable. The parameters of the model were estimated by multiple linear regression using StatGraphics Centurion XV (StatPoint Technologies Inc., Warrenton, VA), a software tool for the creation and analysis of experimental designs.

Furthermore, experiments under optimized conditions but in pulsed mode also were carried out. To evaluate the effect of glycation on emulsifying properties of SC, $\mathrm{O} / \mathrm{W}$ emulsions containing SC glycated with Gal, Lac, and $\mathrm{DX}_{10}$ were prepared under optimized US operating conditions. All emulsions were made in triplicate.

Ultra-Turrax Homogenization. For comparison purposes, an Ultra-Turrax type TP 18/10 rotary homogenizer (IKA Werke GmbH \& Co., Staufen, Germany) working at 16,000 rpm for 1 min was employed for the preparation of emulsions with an oil:SC solution ratio of 1:4 (vol:vol) and $0.5 \mathrm{mg} / \mathrm{mL} \mathrm{SC}$ solutions as the emulsifying agent. Control of temperature during homogenization was carried out as described previously for ultrasonic emulsification.

\section{Emulsifying Properties Determination}

Both the emulsifying activity and stability of native and glycated SC, together with those of controls (control heated SC, control heated SC+carbohydrate), were evaluated by spectroturbidity (Pearce and Kinsella, 1978; Chobert et al., 1988). For emulsifying activity determination, $10 \mu \mathrm{L}$ was taken immediately after the emulsion was formed and was diluted 1,000-fold into $0.1 \%$ (wt/vol) SDS in $0.1 \mathrm{M} \mathrm{NaCl}, \mathrm{pH}$ 7.0. The tubes were inverted 3 times to obtain homogeneous mixtures, and then absorbance at $500 \mathrm{~nm}$ was recorded using a Beckman DU 70 spectrophotometer (Beckman Instruments Inc., Fullerton, CA). The emulsifying activity was expressed as its EAI $\left(\mathrm{m}^{2} / \mathrm{g}\right)$ :

$$
\mathrm{EAI}=2 T d / \phi c,
$$

where $T$ is turbidity $=2.303 \mathrm{~A} / l(\mathrm{~A}=$ absorbance at $500 \mathrm{~nm}$ and $l=$ light path in meters $\left.=10^{-2}\right), \phi$ is the oil phase volume ratio $(0.2), c$ is the protein concentration in $\mathrm{g} / \mathrm{m}^{3}$, and $d$ is the dilution factor $(1,000)$.

To evaluate the emulsion stability, the stock emulsions prepared above were held at room temperature for 24 h. After stirring for $15 \mathrm{~min}$, aliquots were diluted and turbidity was measured as described above $\left(\mathrm{EAI}_{24 \mathrm{~h}}\right)$. The 24-h-old emulsions were then heated at $80^{\circ} \mathrm{C}$ for 30 min. After cooling to room temperature and stirring, turbidity was again measured as above $\left(\mathrm{EAI}_{80^{\circ} \mathrm{C}}\right)$. The emulsion stability was calculated as follows:

$$
\Delta \mathrm{EAI} \%=\left[\left(\mathrm{EAI}_{\max }-\mathrm{EAI}_{80^{\circ} \mathrm{C}}\right) /\left(\mathrm{EAI}_{\max }\right)\right] \times 100,[3]
$$

where $\mathrm{EAI}_{\max }$ is the maximum value between EAI and $\mathrm{EAI}_{24 \mathrm{~h}}$. The smaller the value of $\Delta \mathrm{EAI} \%$, the better the stability. 


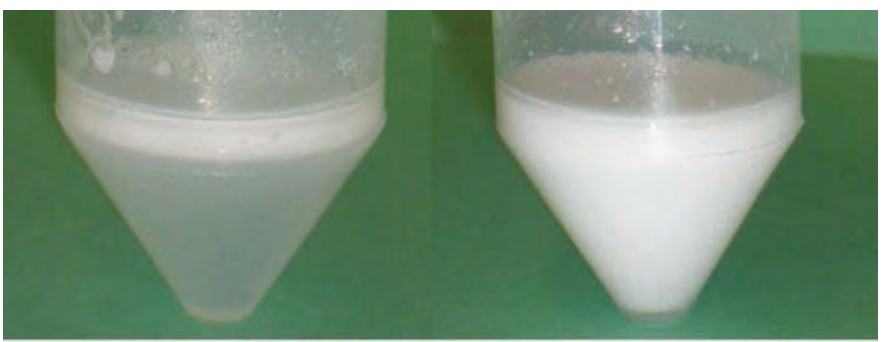

Agitated emulsion

Sonicated emulsion

Figure 1. Aspect of sodium caseinate emulsions immediately after their formation obtained by conventional Ultra-Turrax homogenizer (IKA Werke GmbH \& Co., Staufen, Germany) or high-intensity ultrasound. Color version available in the online PDF.

\section{Statistical Analysis}

Statistical analysis was performed using SPSS for Windows version 17.0. Univariate ANOVA (significant minimum difference test) was used for the statistical evaluation of emulsification results of the glycated and unglycated SC. Differences were considered significant when $P<0.05$.

\section{RESULTS AND DISCUSSION}

\section{Ultrasound Emulsification and Classical Homogenization by Ultra-Turrax}

With the purpose of comparing the effectiveness of forming emulsions by both HI-US and conventional homogenization by Ultra-Turrax, emulsions containing $0.5 \mathrm{mg} / \mathrm{mL} \mathrm{SC}$ solutions as the emulsifying agent were formed using both techniques. The EAI of emulsion homogenized with Ultra-Turrax $\left(77.61 \pm 4.89 \mathrm{~m}^{2} / \mathrm{g}\right)$ was much lower than that of the sonicated emulsions (>785 $\mathrm{m}^{2} / \mathrm{g}$; Table 3 ) at $0.5 \mathrm{mg}$ of $\mathrm{SC} / \mathrm{mL}$, regardless of US amplitude and time assayed. These results could be attributed to the smaller particle size of emulsions obtained by HI-US as a higher turbidity corresponds to a smaller particle size ( $\mathrm{Mu}$ et al., 2006). Indeed, greater homogenization can be appreciated by sight, as observed in Figure 1. This is consistent with results from previous investigations, according to which, for a given system and at a fixed surfactant concentration, sonicated emulsions are finer than agitated ones, likely due to a rather important foam formation in the case of classical mechanical agitation (Abismaïl et al., 1999; Canselier et al., 2002).

\section{Optimization of the US Operating Conditions}

The formation of emulsions requires energy input to break up the oil into droplets and a surfactant (i.e., protein) to lower the surface tension. Several phenomena take place simultaneously during the formation of emulsions, such as the adsorption of the surfactant, the break-up of the dispersed phase, and the stability of the newly formed particles (Darewicz and Dziuba, 2001), which depend on the manner in which the emulsion is processed. Optimizing the emulsification process ranges from choosing a suitable emulsifier and its concentration, to the establishment of optimal processing conditions (Sánchez et al., 1998). As described in the Materials and Methods section, selection of optimal US operating conditions to maximize EAI was carried out using a Box-Behnken experimental design. Multiple linear regression was applied to calculate the parameters of the proposed quadratic equation (Eq. 1), and the statistical significance of the estimated regression coef-

Table 3. Box-Behnken design with experimental values for the emulsifying activity $(\mathrm{EAI})$ and stability $(\Delta \mathrm{EAI}$, \%) indices ${ }^{1}$ obtained by high-intensity ultrasound

\begin{tabular}{lcccc}
\hline $\begin{array}{l}\text { Protein concentration, } \\
\mathrm{mg} / \mathrm{mL}\end{array}$ & $\begin{array}{c}\text { Amplitude, } \\
\%\end{array}$ & $\begin{array}{c}\text { Ultrasound } \\
\text { time, } \mathrm{s}\end{array}$ & $\begin{array}{l}\text { EAI, } \\
\mathrm{m}^{2} / \mathrm{g}\end{array}$ & $\Delta$ EAI\% \\
\hline 0.5 & 40 & 20 & $1,021.00 \pm 7.19$ & $85.83 \pm 0.75$ \\
4.5 & 40 & 20 & $162.92 \pm 11.29$ & $46.58 \pm 5.04$ \\
2.5 & 20 & 20 & $180.80 \pm 8.99$ & $25.00 \pm 3.05$ \\
4.5 & 60 & 40 & $202.99 \pm 11.72$ & $46.31 \pm 11.89$ \\
4.5 & 40 & 60 & $182.38 \pm 5.81$ & $1.48 \pm 1.23$ \\
0.5 & 40 & 60 & $1,181.75 \pm 14.08$ & $87.66 \pm 0.84$ \\
0.5 & 20 & 40 & $784.86 \pm 24.95$ & $80.18 \pm 0.24$ \\
2.5 & 60 & 60 & $312.32 \pm 34.26$ & $32.22 \pm 6.63$ \\
2.5 & 20 & 60 & $233.49 \pm 19.61$ & $51.81 \pm 0.70$ \\
2.5 & 60 & 20 & $273.60 \pm 16.02$ & $25.49 \pm 5.48$ \\
4.5 & 20 & 40 & $127.55 \pm 1.22$ & $37.11 \pm 9.90$ \\
0.5 & 60 & 40 & $1,286.76 \pm 8.41$ & $89.94 \pm 0.87$ \\
2.5 & 40 & 40 & $292.36 \pm 9.31$ & $37.79 \pm 1.19$ \\
2.5 & 40 & 40 & $285.82 \pm 7.95$ & $39.11 \pm 1.77$ \\
2.5 & 40 & 40 & $278.88 \pm 14.20$ & $36.72 \pm 1.75$ \\
\hline
\end{tabular}

${ }^{1}$ Data represent the mean of triplicate determinations. 
ficients was analyzed. After excluding model terms not significantly different from $0(P>0.10)$ and refitting, the following equation was obtained:

$$
\begin{aligned}
\mathrm{EAI} & =926.039-560 C+11.344 A \\
& +88.327 C^{2}-2.665 C A .
\end{aligned}
$$

The fitted model explains $98 \%$ of the variability in EAI, and the standard deviation of the residuals was 65.13. According to the experimental design, the US factor with the highest influence on emulsifying properties was found to be the SC concentration. Emulsions stabilized with $0.5 \mathrm{mg} / \mathrm{mL}$ SC solutions provided significantly higher EAI values (785 to $1,287 \mathrm{~m}^{2} / \mathrm{g}$ ) than those obtained at higher protein concentrations (128 to $312 \mathrm{~m}^{2} / \mathrm{g}$ ), regardless of other experimental conditions (Table 3). According to Canselier et al. (2002), the droplet size, which determines emulsion formation and stability, is reduced when the surfactant concentration increases until a plateau is reached. Therefore, in our case, it is likely that such a plateau had been reached around $0.5 \mathrm{mg}$ of $\mathrm{SC} / \mathrm{mL}$, with remaining unadsorbed caseinate at higher concentrations $(2.5$ and $4.5 \mathrm{mg}$ of $\mathrm{SC} / \mathrm{mL}$ ). Furthermore, it has been reported that whereas $\beta$-casein, a major protein in $\mathrm{SC}$ together with $\alpha_{S 1}$-casein, is preferentially adsorbed in emulsions made at relatively low levels of $\mathrm{SC}, \alpha_{\mathrm{S}_{1}}$-casein, less hydrophobic and surface active than $\beta$-casein (Mitchell et al., 1970; Dickinson et al., 1988), is preferentially adsorbed in emulsions containing substantial levels of unadsorbed caseinate (Srinivasan et al., 1996). Based on this, we hypothesize that the protein preferentially adsorbed in our emulsion at $0.5 \mathrm{mg}$ of $\mathrm{SC} / \mathrm{mL}$ might be $\beta$-casein, with better emulsifying activity than $\alpha_{S_{1}}$-casein.

The amplitude of US wave oscillation is one of the most important factors influencing the efficient transformation of energy into cavitation (Hielscher, 2005). At $0.5 \mathrm{mg}$ of $\mathrm{SC} / \mathrm{mL}$, the highest EAI value $(1,286.76$ $\mathrm{m}^{2} / \mathrm{g}$ ) was obtained for a sonication time of $40 \mathrm{~s}$ and the maximum amplitude assayed (i.e., $60 \%$, probably due to the more effective creation of cavitation than with 20 or $40 \%$ amplitude). In a similar way, the highest values of EAI at higher concentrations, 2.5 and $4.5 \mathrm{mg}$ of SC/ $\mathrm{mL}$ also were obtained with a $60 \%$ amplitude (Table 3 ). Nevertheless, in spite of the high EAI values obtained, the SC emulsions were generally unstable under all assayed conditions, with $\triangle \mathrm{EAI}$ values ranging from 25 to 90\% (Table 3).

Finally, at these conditions of SC concentration $(0.5$ $\mathrm{mg}$ of $\mathrm{SC} / \mathrm{mL}$ ), amplitude of oscillation $(60 \%)$, and sonication time $(40 \mathrm{~s})$, the use of pulsed-US emulsification also was considered. The application of 2 pulses of $20 \mathrm{~s}$ with an interval of $10 \mathrm{~s}$ between them led to an increase in EAI $(1,329.52 \pm 0.98$ vs. $1,286 \pm 8.41$ in continuous mode) and a decrease in $\triangle \mathrm{EAI} \%$ (6.65 \pm 0.15 vs. $89.94 \pm 0.87$ ), suggesting that the less energy intensive pulsed mode favors the emulsification process. A possible explanation for this might be that the application of $60 \%$ amplitude for $40 \mathrm{~s}$ in continuous mode could give rise to a slightly excessive cavitation, and then to a small loss of active matter for SC (Abismail et al., 1999).

\section{Emulsifying Properties of SC Glycoconjugates}

The $\mathrm{O} / \mathrm{W}$ emulsions containing $\mathrm{SC}$ glycoconjugates as emulsifiers were formed under optimal US operating conditions (i.e., at $0.5 \mathrm{mg}$ of $\mathrm{SC} / \mathrm{mL}$; an US amplitude of $60 \%$; and a sonication time of $40 \mathrm{~s}$ in pulsed mode, 2 duty cycles of $20 \mathrm{~s}$ ).

Effect of Heat Treatment. Heating at $60^{\circ} \mathrm{C}$ for 4 $\mathrm{h}$ did not seem to modify noticeably the emulsifying activity of control SC compared with native SC (EAI $\left.=1,329.52 \mathrm{~m}^{2} / \mathrm{g}\right)$. However, control $\mathrm{SC}$ subjected to a more intensive heat treatment $\left(8 \mathrm{~h}\right.$ at $\left.60^{\circ} \mathrm{C}\right)$ showed a significantly lower EAI value (Figure 2) and worse stabilizing properties (Figure 3) than native SC. This is in agreement with the results of Chobert et al. (1988) who, in a study with casein-stabilized emulsions obtained by homogenizing in a Waring blender, reported that, above $\mathrm{pH}$ 6.0, heat treatment decreased EAI. As observed in Table 4, the apparent particle size of control heated $\mathrm{SC}$ in the absence of sugars showed a gradual increase compared with native SC as incubation proceeded, indicating the formation of some minor aggregated forms during heating, probably due to hydrophobic interactions. This could affect the diffusion of SC from bulk to interface $\mathrm{O} / \mathrm{W}$ and make the adsorption process of the protein at the interface slower, reducing the ability of protein to form and stabilize emulsions (Ma et al., 2009).

Moreover, as observed in Figure 2, emulsion containing control heated $\mathrm{SC}+\mathrm{Lac}\left(8 \mathrm{~h}, 60^{\circ} \mathrm{C}\right)$ as the emulsifier agent showed a higher EAI value than emulsion with control heated $\mathrm{SC}\left(8 \mathrm{~h}, 60^{\circ} \mathrm{C}\right)$ without Lac. However, no significant differences were found between control heated $\mathrm{SC}\left(8 \mathrm{~h}, 60^{\circ} \mathrm{C}\right)$ and control heated $\mathrm{SC}+\mathrm{Gal} /$ $\mathrm{DX}_{10}$. This suggests that the presence of lactose during emulsion formation causes a slight increase in the surface activity of SC. A similar effect of sucrose, another disaccharide, on the surface behavior of SC at the airwater interface was noted by Antipova et al. (1999). They attributed such results to the increase in protein surface hydrophobicity due to a slight dissociation of $\mathrm{SC}$ micelles as a result of interaction with sucrose in the bulk aqueous medium. 


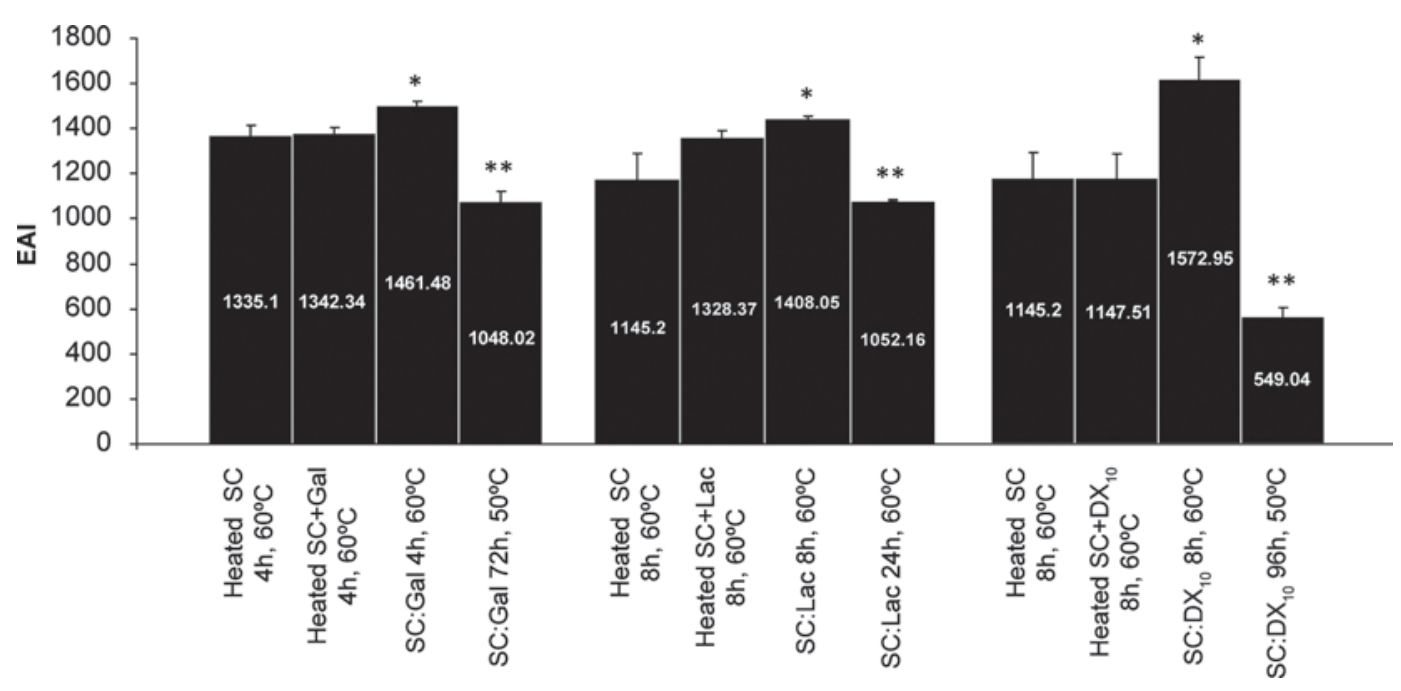

Figure 2. Effect of heat treatment and free carbohydrate in aqueous solution following early-stage and advanced glycation with galactose (Gal), lactose (Lac), and $10 \mathrm{kDa}$ dextran $\left(\mathrm{DX}_{10}\right)$ on emulsifying activity (EAI) of sodium caseinate (SC). Data points represent the mean of triplicate determinations with error bars indicating the standard deviations. Emulsifier concentration: $0.5 \mathrm{mg} / \mathrm{mL}$, ultrasound amplitude $=60 \%$, and sonication time $=40 \mathrm{~s}$ (duty cycles $20 \mathrm{~s}$ ). *Indicates a significant difference between glycoconjugates obtained in the early stages of the Maillard reaction and the corresponding controls $(P<0.05)$. **Indicates a significant difference between glycoconjugates obtained at both early and advanced stages of the Maillard reaction $(P<0.05)$.

Effect of Early-Stage Glycation on SC Emulsifying Properties. Glycation at the early stages of MR was found to improve significantly the EAI of US-treated SC, regardless the employed carbohydrate. Thus, SC:Gal $\left(4 \mathrm{~h}, 60^{\circ} \mathrm{C}\right)$, SC:Lac $\left(8 \mathrm{~h}, 60^{\circ} \mathrm{C}\right)$ and $\mathrm{SC}: \mathrm{DX}_{10}\left(8 \mathrm{~h}, 60^{\circ} \mathrm{C}\right)$ conjugates exhibited higher EAI values than those of the corresponding control heated
$\mathrm{SC}+$ carbohydrate (controls formed by SC and carbohydrate separately heated and mixed just before analysis in which the MR has not taken place) and control heated SC (Figure 2). This suggests that the observed improvement in functionality was due to the covalent conjugation of the protein with carbohydrates. The increased emulsifying activity of Maillard complexes

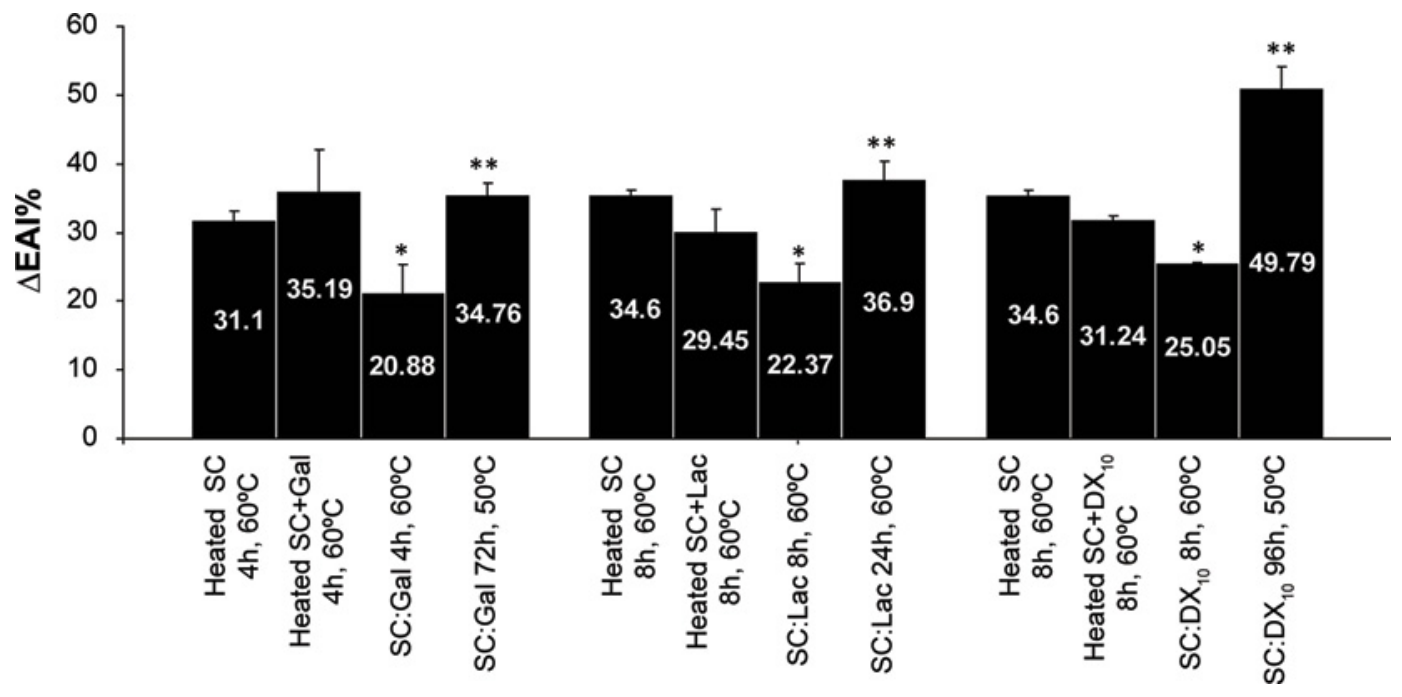

Figure 3. Effect of heat treatment and free carbohydrate in aqueous solution following early-stage and advanced glycation with galactose (Gal), lactose (Lac), and $10 \mathrm{kDa}$ dextran $\left(\mathrm{DX}_{10}\right)$ on emulsifying stability $(\Delta \mathrm{EAI} \%)$ of sodium caseinate $(\mathrm{SC})$. Data points represent the mean of triplicate determinations with error bars indicating the standard deviations. Emulsifier concentration: $0.5 \mathrm{mg} / \mathrm{mL}$, ultrasound amplitude $=$ $60 \%$, and sonication time $=40 \mathrm{~s}$ (duty cycles $20 \mathrm{~s}$ ). ${ }^{*}$ Indicates a significant difference between glycoconjugates obtained at the early stages of the Maillard reaction and the corresponding controls $(P<0.05)$. **Indicates a significant difference between glycoconjugates obtained at both early and advanced stages of the Maillard reaction $(P<0.05)$. 
Table 4. Variation of apparent particle diameter as a function of incubation time for control heated sodium caseinate (SC) and SC glycated with galactose (Gal), lactose (Lac), and $10 \mathrm{kDa}$ dextran $\left(\mathrm{DX}_{10}\right)$

\begin{tabular}{llc}
\hline Sample & $\begin{array}{l}\text { Time and } \\
\text { temperature conditions }\end{array}$ & $\begin{array}{c}\text { Apparent particle } \\
\text { diameter, nm }\end{array}$ \\
\hline Controls & & \\
Native SC & 0 & $184.53 \pm 0.65$ \\
Control heated SC & $4 \mathrm{~h}, 60^{\circ} \mathrm{C}$ & $295.02 \pm 3.41$ \\
Control heated SC & $8 \mathrm{~h}, 60^{\circ} \mathrm{C}$ & $314.04 \pm 6.05$ \\
Glycoconjugates & & \\
SC:Gal & $4 \mathrm{~h}, 60^{\circ} \mathrm{C}$ & $671.06 \pm 9.53$ \\
SC:Gal & $72 \mathrm{~h}, 50^{\circ} \mathrm{C}$ & $2,060.47 \pm 40.26$ \\
SC:Lac & $8 \mathrm{~h}, 60^{\circ} \mathrm{C}$ & $421.49 \pm 2.11$ \\
SC:Lac & $24 \mathrm{~h}, 60^{\circ} \mathrm{C}$ & $757.12 \pm 1.97$ \\
SC:DX & $8 \mathrm{~h}, 60^{\circ} \mathrm{C}$ & $1,047.34 \pm 39.56$ \\
SC:DX & $96 \mathrm{~h}, 50^{\circ} \mathrm{C}$ & $1,156.05 \pm 51.51$ \\
\hline
\end{tabular}

could be attributed to the faster and stronger adsorption of the protein at the emulsion interface. This was likely due to the more amphiphilic character of glycated protein because of glycation-induced exposure of new hydrophobic areas on the protein surface and the added hydrophilicity given by the covalently linked carbohydrate (Hattori et al., 1997; Darewicz and Dziuba, 2001). In this respect, despite the limited extent of the MR between SC and $\mathrm{DX}_{10}$ (Corzo-Martínez et al., 2010), glycation with $\mathrm{DX}_{10}$ led to a higher improvement in EAI of SC over that of Gal and Lac (Figure 2 ), probably because of its higher hydrophilic character (Dickinson, 2008).

Likewise, glycoconjugates at the early stages of the MR also showed a significant improvement in emulsifying stability $(\triangle \mathrm{EAI} \%)$ with respect to the corresponding control heated SC and control heated SC + carbohydrate (Figure 3). For galactosyl and lactosyl systems, this improvement in emulsion stability could be attributed to the decrease in hydrophobic interactions of SC due to the loss of available lysine (O'Connell and Fox, 1999), as well as to the higher electrostatic-steric repulsive forces between the molecules of glycated SC versus unmodified SC (Darewicz and Dziuba, 2001). This inhibition of hydrophobic interactions and promotion of electro-steric repulsion between the oil droplets prevent rapid coalescence and flocculation, and produce stable emulsions with glycated SC. Such emulsion stability was particularly improved with galactosylated SC, likely because of the higher glycation degree compared with lactosylated SC (Corzo-Martínez et al., 2010).

In the case of emulsions containing SC:DX ${ }_{10}$ conjugate as the emulsifier, their improved stability compared with unmodified SC is likely related to the larger size and hydrophilicity of the polysaccharide moiety. This, oriented to the aqueous layer, creates an additional bulky layer on the droplet surface, preventing coalescence and flocculation through steric stabilization or polysaccharide entanglements (resulting in localized regions of high viscosity associated with the O/W interface; Shepherd et al., 2000; Fechner et al., 2007; Dickinson, 2009). Moreover, $\mathrm{DX}_{10}$ could control the rheology and network structure of the continuous phase, retarding phase separation and gravity-induced creaming (Dickinson, 2008).

Effect of Advanced Glycation on SC Emulsifying Properties. Conversely, glycoconjugates at the advanced stages of the MR (SC:Gal for $72 \mathrm{~h}$ at $50^{\circ} \mathrm{C}$, $\mathrm{SC}: \mathrm{Lac}$ for $24 \mathrm{~h}$ at $60^{\circ} \mathrm{C}$, and $\mathrm{SC}: \mathrm{DX}_{10}$ for $96 \mathrm{~h}$ at $50^{\circ} \mathrm{C}$ ) showed significantly reduced emulsifying activity and stability compared with conjugates at the early stages of the MR (Figures 2 and 3). As observed in Table 4, the mean particle size of SC:Gal conjugates at $50^{\circ} \mathrm{C}$, as well as SC:Lac systems at $60^{\circ} \mathrm{C}$ increased significantly over time, particularly for galactosylated SC. This indicated that extensive glycation of SC promoted its polymerization mainly through covalent cross-linking, produced at the most advanced stages of the MR, likely affecting the diffusion of $\mathrm{SC}$ from bulk to $\mathrm{O} / \mathrm{W}$ interface and slowing the reorientation process of the protein at the interface (Dickinson and Semenova, 1992). Conversely, for SC glycated with $\mathrm{DX}_{10}$, apparent particle size showed little change over incubation time, probably due to the limited progress of the MR toward the more advanced stages under these conditions (Corzo-Martínez et al., 2010). However, because of the larger size of $\mathrm{DX}_{10}$ compared with Gal and Lac, and the higher glycation degree of $\mathrm{SC}$ glycated with $\mathrm{DX}_{10}$ at $50^{\circ} \mathrm{C}$ for $96 \mathrm{~h}$ than at $60^{\circ} \mathrm{C}$ for $8 \mathrm{~h}$ (Corzo-Martínez et al., 2010), it is likely that the reduction in emulsifying activity and stability was due to a decrease in protein surface hydrophobicity because of the shielding of hydrophobic patches on the SC surface by covalently attached $\mathrm{DX}_{10}$.

In conclusion, the results presented in this work prove the usefulness of US as an efficient alternative to conventional stirring in the formation of $\mathrm{O} / \mathrm{W}$ emulsions containing native bovine $\mathrm{SC}$ as an emulsifier agent. Our findings also show that the use of MR complexes of SC 
with mono-, di-, and polysaccharides obtained at the early stages of glycation in combination with HI-US as the emulsification system gave rise to better and more stable $\mathrm{O} / \mathrm{W}$ emulsions than did native $\mathrm{SC}$.

\section{ACKNOWLEDGMENTS}

This work was supported by Consolider Ingenio 2010 Programme FUN-C-FOOD CSD2007-00063 and project AGL2007-63462/ALI (Ministerio de Educación y Ciencia) and ALIBIRD S2009/AGR-1469 (Comunidad de Madrid).

\section{REFERENCES}

Abismaïl, B., J. P. Canselier, A. M. Wilhelm, H. Delmas, and C. Gourdon. 1999. Emulsification by ultrasound: Drop size distribution and stability. Ultrason. Sonochem. 6:75-83.

Akinshina, A., R. Ettelaie, E. Dickinson, and G. Smyth. 2008. Interactions between adsorbed layers of $\alpha_{S_{1}}$-casein with covalently bound side chains: A self-consistent field study. Biomacromolecules 9:3188-3200.

Aminlari, M., R. Ramezani, and F. Jadidi. 2005. Effect of Maillardbased conjugation with dextran on the functional properties of lysozyme and casein. J. Sci. Food Agric. 85:2617-2624.

Antipova, A. S., M. G. Semenova, and L. E. Belyakova. 1999. Effect of sucrose on the thermodynamic properties of ovalbumin and sodium caseinate in bulk solution and at air-water interface. Colloids Surf. B Biointerfaces 12:261-270.

Behrend, O., and K. A. X. Schubert. 2000. Influence of continuous phase viscosity on emulsification by ultrasound. Ultrason. Sonochem. 7:77-85.

Bondy, C., and K. Söllner. 1935. On the mechanism of emulsification by ultrasonic waves. Trans. Faraday Soc. 31:835-842.

Camino, N. A., O. E. Pérez, and A. M. R. Pilosof. 2009. Molecular and functional modification of hydroxypropylmethylcellulose by highintensity ultrasound. Food Hydrocoll. 23:1089-1095.

Canselier, J. P., H. Delmas, A. M. Wilhelm, and B. Abismaïl. 2002. Ultrasound emulsification-An overview. J. Dispersion Sci. Technol. 23:333-349.

Chobert, J. M., M. Z. Sitohy, and J. R. Whitaker. 1988. Solubility and emulsifying properties of caseins modified enzymatically by Staphylococcus aureus V8 protease. J. Agric. Food Chem. 36:220-224.

Corzo-Martínez, M., F. J. Moreno, M. Villamiel, and F. M. Harte. 2010. Characterization and improvement of rheological properties of sodium caseinate glycated with galactose, lactose and dextran. Food Hydrocoll. 24:88-97.

Cucheval, A., and R. C. Y. Chow. 2008. A study on the emulsification of oil by power ultrasound. Ultrason. Sonochem. 15:916-920.

Darewicz, M., and J. Dziuba. 2001. The effect of glycosylation on emulsifying and structural properties of bovine $\beta$-casein. Nahrung/Food 45:15-20.

Dickinson, E. 2008. Interfacial structure and stability of food emulsions as affected by protein-polysaccharide interactions. Soft Matter 4:932-942.

Dickinson, E. 2009. Hydrocolloids as emulsifiers and emulsion stabilizers. Food Hydrocoll. 23:1473-1482.

Dickinson, E., S. E. Rolfe, and D. G. Dalgleish. 1988. Competitive adsorption of $\alpha_{\mathrm{s} 1}$-casein and $\beta$-casein in oil-in-water emulsions. Food Hydrocoll. 2:397-405.

Dickinson, E., and M. G. Semenova. 1992. Emulsifying properties of covalent protein-dextran hybrids. Colloids Surf. 64:299-310.

Einhorn-Stoll, U., M. Ulbrich, S. Sever, and H. Kunzek. 2005. Formation of milk protein-pectin conjugates with improved emulsifying properties by controlled dry heating. Food Hydrocoll. 19:329340.
Ennis, M. P., and D. M. Mulvihill. 2000. Milk proteins. Pages 189-217 in Handbook of Hydrocolloids. G. Phillips and P. Williams, ed. Woodhead Publishing, Cambridge, UK.

Fechner, A., A. Knoth, I. Scherze, and G. Muschiolik. 2007. Stability and release properties of double-emulsions stabilised by caseinatedextran conjugates. Food Hydrocoll. 21:943-952.

Gaikwad, S. G., and A. B. Pandit. 2008. Ultrasound emulsification: Effect of ultrasonic and physicochemical properties on dispersed phase volume and droplet size. Ultrason. Sonochem. 15:554-563.

Hattori, M., A. Ogino, H. Nakai, and F. Takahashi. 1997. Functional improvement of $\beta$-lactoglobulin by conjugating with alginate lyaselyase. J. Agric. Food Chem. 45:703-708.

Hielscher, T. 2005. Ultrasonic production of nano-size dispersions and emulsions. In ENS'05, Paris, France. http://hdl.handle. net $/ 2042 / 6282$.

Knorr, D., M. Zenker, V. Heinz, and D. U. Lee. 2004. Applications and potential of ultrasonics in food processing. Trends Food Sci. Technol. 15:261-266.

Lauterborn, W., and C. D. Ohl. 1997. Cavitation bubble dynamics. Ultrason. Sonochem. 4:65-75.

Ma, H., P. Forssell, R. Partanen, R. Seppänen, J. Buchert, and H. Boer. 2009. Sodium caseinates with an altered isoelectric point as emulsifiers in oil/water systems. J. Agric. Food Chem. 57:38003807 .

Mitchell, J., L. Irons, and G. J. Palmer. 1970. A study of the spread and adsorbed films of milk proteins. Biochim. Biophys. Acta 200:138-150.

Moreno, F. J., R. Lopez-Fandino, and A. Olano. 2002. Characterization and functional properties of lactosyl caseinomacropeptide conjugates. J. Agric. Food Chem. 50:5179-5184.

Morris, G. A., I. M. Sims, A. J. Robertson, and R. H. Furneaux. 2004. Investigation into the physical and chemical properties of sodium caseinate-maltodextrin glyco-conjugates. Food Hydrocoll. 18:1007-1014

Mu, M., X. Pan, P. Yao, and M. Yiang. 2006. Acidic solution properties of $\beta$-casein-graft-dextran copolymer prepared through Maillard reaction. J. Colloid Interface Sci. 301:98-106.

O'Connell, J. E., and P. F. Fox. 1999. Heat-induced changes in the calcium sensitivity of caseins. Int. Dairy J. 9:839-847.

O'Regan, J., and D. M. Mulvihill. 2009. Preparation, characterisation and selected functional properties of sodium caseinate-maltodextrin conjugates. Food Chem. 115:1257-1267.

Oliver, C. M., L. D. Melton, and R. A. Stanley. 2006a. Creating proteins with novel functionality via the Maillard reaction: A review. Crit. Rev. Food Sci. Nutr. 46:337-350.

Oliver, C. M., L. D. Melton, and R. A. Stanley. 2006b. Functional properties of caseinate glycoconjugates prepared by controlled heating in the dry state. J. Sci. Food Agric. 86:732-740.

Patist, A., and D. Bates. 2008. Ultrasonic innovations in the food industry: From the laboratory to commercial production. Innov. Food Sci. Emerg. Technol. 9:147-154.

Pearce, K. N., and J. E. Kinsella. 1978. Emulsifying properties of proteins: Evaluation of a turbidimetric technique. J. Agric. Food Chem. 26:716-723.

Pongsawatmanit, R., T. Harnsilawat, and D. J. McClements. 2006. Influence of alginate, $\mathrm{pH}$ and ultrasound treatment on palm oilin-water emulsions stabilized by $\beta$-lactoglobulin. Colloids Surf. A Physicochem. Eng. Asp. 287:59-67.

Sánchez, M. C., M. Berjano, A. Guerrero, and C. Gallegos. 1998. Evolution of the microstructure and rheology of $\mathrm{O} / \mathrm{W}$ emulsions during the emulsification process. Can. J. Chem. Eng. 76:479-485.

Shepherd, R., A. Robertson, and D. Ofman. 2000. Dairy glycoconjugate emulsifiers: Casein-maltodextrins. Food Hydrocoll. 14:281286.

Soria, A. C., and M. Villamiel. 2010. Effect of ultrasound on the technological properties and bioactivity of food: A review. Trends Food Sci. Technol. 21:323-331.

Srinivasan, M., H. Singh, and P. A. Munro. 1996. Sodium caseinatestabilized emulsions: Factors affecting coverage and composition of surface proteins. J. Agric. Food Chem. 44:3807-3811. 